Full Length Article

\title{
Synthesis of biofunctional coating for a TiZr alloy: Surface, electrochemical, and biological characterizations
}

\author{
Jairo M. Cordeiro ${ }^{\mathrm{a}, \mathrm{b}, 1}$, Heloisa N. Pantaroto ${ }^{\mathrm{a}, 1}$, Emanuella M. Paschoaleto $^{\mathrm{a}}$, Elidiane C. Rangel ${ }^{\mathrm{c}}$, \\ Nilson C. da Cruz $^{c}$, Cortino Sukotjo ${ }^{\text {b,d }}$, Valentim A.R. Barão ${ }^{\text {a,b,* }}$ \\ ${ }^{a}$ University of Campinas (UNICAMP), Piracicaba Dental School, Department of Prosthodontics and Periodontology, Av. Limeira, 901, Piracicaba, São Paulo 13414-903, Brazil \\ ${ }^{\mathrm{b}}$ Institute of Biomaterials, Tribocorrosion and Nanomedicine, Brazilian Branch (IBTN/Br), Brazil \\ ${ }^{\mathrm{c}}$ Univ. Estadual Paulista (UNESP), Engineering College, Laboratory of Technological Plasmas, Av. Três de Março, 511, Sorocaba, São Paulo 18087-180, Brazil \\ ${ }^{\mathrm{d}}$ University of Illinois at Chicago, College of Dentistry, Department of Restorative Dentistry, 801 S. Paulina, Chicago, IL 60612, USA
}

\section{A R T I C L E I N F O}

\section{Article history:}

Received 2 March 2018

Revised 29 April 2018

Accepted 7 May 2018

Available online 8 May 2018

\section{Keywords:}

Alloys

Titanium

Dental implants

Corrosion

Biofilms

Proteins

\begin{abstract}
A B S T R A C T
This study formed a biofunctional coating for a Ti15Zr alloy to improve the surface characteristics, the electrochemical behavior, and the biological properties of this implant material. Ti15Zr discs ( $15 \mathrm{~mm}$ in diameter $\times 1 \mathrm{~mm}$ thickness) were obtained in three versions: machined, SLA ${ }^{\circledR}$-treated (control groups), and modified by plasma electrolytic oxidation (PEO) (experimental group). Surface features such as topography, composition, surface roughness, surface free energy, and hardness were assessed. Electrochemical tests were conducted with body fluid solution ( $\mathrm{pH}$ 7.4). The albumin protein adsorption was measured by the bicinchoninic acid method, and the adhesion of Streptococcus sanguinis was determined. The surface treatments modified the material's topography. SLA promoted surface roughness higher than that of the other groups, whereas PEO surfaces presented the highest values of hardness and surface free energy. PEO increased the polarization resistance and the corrosion potential, and decreased capacitance and corrosion current density values. In addition, plasma treatment improved the albumin adsorption without being favorable to biofilm adhesion. PEO appears to be the most promising alternative for Ti15Zr alloys, since it improved surface characteristics and electrochemical behavior, as well as enhancing the adsorption of albumin on the material surface with fewer tendencies to bacterial adhesion.
\end{abstract}

(c) 2018 Elsevier B.V. All rights reserved.

\section{Introduction}

Titanium (Ti) alloy containing zirconium $(\mathrm{Zr})$ as $\mathrm{Ti} 15 \mathrm{Zr}$ is a promising material in implantology and is used to manufacture narrow-diameter implants $(<3.5 \mathrm{~mm})$, which are reliable options in rehabilitation with reduced mesiodistal and/or interradicular space or in edentulous ridges with severe reabsorption [1]. This material is commercially available as implants (Roxolid ${ }^{\circledR}$, Institut Straumann AG, Basel, Switzerland) and has demonstrated acceptable success rates and clinical performance comparable with that of commercially pure titanium (cpTi) [2]. Its application has emerged and become established in implant dentistry due to the high levels of mechanical strength and excellent biocompatibility

* Corresponding author at: University of Campinas (UNICAMP), Piracicaba Dental School, Department of Prosthodontics and Periodontology, Av. Limeira, 901, Piracicaba, São Paulo, 13414-903, Brazil.

E-mail address: vbarao@unicamp.br (V.A.R. Barão).

1 The authors share the position of first author. properties [1], and it can be considered a solution to the potential toxic effects [3] and peri-implant consequences of the Ti6Al4V alloy [4].

Adverse peri-implant effects may be caused by material degradation as a result of the release of metal ions and debris in the body. Osteolysis, bone resorption, and infections, as well as implant loosening and failure [3,5], are some negative outcomes that can occur if implant surfaces are not modified to tolerate physiological changes in the environment [6]. In addition to protecting the implant surface against corrosive and degradation processes, surface treatments can also ensure better mechanical, physical, and biological properties [7].

The surface derived by the process involving sandblasting followed by acid-etching (SLA) has demonstrated excellent clinical results when applied in implants [8], including those made by the Ti15Zr alloy. SLA implants have shown great cell differentiation and bone apposition, with strong bone-implant contact in the initial periods of osseointegration [9]. Another surface treatment that has shown promising results is plasma electrolytic oxidation (PEO), 
a high-voltage anodic oxidation process in electrolytic solutions [10] with good interfacial adhesion to cpTi and its alloys [11]. PEO forms rough, porous, and thick coatings [10,12], providing greater surface area for implant attachment to the bone, as well as excellent biocompatibility and osseointegration [13]. Additionally, the use of different electrolytes permits the incorporation of elements that can provide antibacterial effects $[14,15]$, contribute to a more bioactive surface $[10,16]$ and enhance protein adsorption [17], as well as being beneficial to the electrochemical behavior of the material $[12,17]$.

PEO has been widely used in cpTi [12,18] and its alloys [19-21]. Moreover, to the best knowledge of the authors, it was not found studies that compared Ti15Zr alloys with PEO and SLA surfaces with regard to corrosion, protein adsorption, and biofilm formation, properties that play crucial roles in implant treatment success. Further, if Ti15Zr is to be considered a reliable material in the manufacture of dental implants, it is important that the best treatment in this bulk substrate be established. Thus, this study formed a biofunctional coating for the Ti15Zr alloy, with the aim of improving its surface characteristics, electrochemical behavior, and biological properties. For comparison with well-established surfaces, the machined and SLA surfaces were used as controls.

\section{Materials and methods}

\subsection{Experimental design}

Fig. 1 illustrates the experimental design of this study. Ti15Zr alloy discs [machined (TiZr M) and SLA ${ }^{\circledR}$ surfaces (TiZr SLA)], 15 $\mathrm{mm}$ in diameter and $1 \mathrm{~mm}$ thick, were kindly provided by Institut Straumann AG. For the experimental group, the machined surface was modified by PEO (TiZr PEO). The surface, electrochemical, and biological properties of Ti15Zr alloy were determined.

\subsection{Plasma electrolytical oxidation treatment}

PEO was applied according to our previous protocol $[12,14,17]$. Briefly, Ti15Zr machined discs were used as the anode, while a steel tank with a cooling system was the cathode. The electrolytic solution was prepared by the dissolution of $52.854 \mathrm{~g}$ of calcium acetate [Ca $\left(\mathrm{CH}_{3} \mathrm{CO}_{2}\right)_{2}$ ] (Sigma-Aldrich, St. Louis, MO, USA) and $4.3208 \mathrm{~g}$ of glycerophosphate disodium $\left(\mathrm{C}_{3} \mathrm{H}_{7} \mathrm{Na}_{2} \mathrm{O}_{6} \mathrm{P}\right)$ (SigmaAldrich) in $1 \mathrm{~L}$ of distilled water. The deposition was carried out in $500 \mathrm{~mL}$ of solution during $10 \mathrm{~min}$, two discs at a time. The deposition parameters - voltage $(290 \mathrm{~V})$, frequency $(250 \mathrm{~Hz})$, and duty cycle (60\%) - were controlled by a pulsed DC power supply (Plasma
Technology Ltd.). The treated discs were washed with deionized water and air-dried.

\subsection{Surface characterization}

All samples were ultrasonically cleaned and degreased with deionized water (10 $\mathrm{min}$ ) and $70 \%$ propanol (10 min) (SigmaAldrich) and dried with warm air before the characterization analyses [22]. The surface topography was observed by two- and threedimensional images obtained by a non-contact 3D Laser Scanning Confocal Microscope (LSCM, VK-X200 series, Keyence, Osaka, Japan) $(n=1)$. The images were acquired with lenses of $50 \times$ and $150 \times$ magnification and processed by means of VK-Analyzer software (Keyence v3.3.0.0). The surface area was estimated by the extrapolation of its measurements in images of $100 \times 100 \mu \mathrm{m}$ that were obtained at the $50 \times$ magnification. The surface morphology was also observed by means of scanning electron microscopy (SEM; JEOL JSM-6010LA, Peabody, MA, USA) $(\mathrm{n}=1)$.

The main constituent elements of the Ti15Zr alloy surfaces were assessed by energy-dispersive spectroscopy (EDS) $(n=1)$, which allowed for semiquantitative analysis on the order of $1 \mu \mathrm{m}^{3}$. Xray diffractometry (XRD; X'Pert PRO MRD, PANalytical, Almelo, The Netherlands) was performed to verify the chemical and microstructural composition of the surfaces $(n=1)$. The parameters used were: $\mathrm{Cu}-\mathrm{K} \alpha(\lambda=1.540598 \AA)$ radiation and operation at $45 \mathrm{kV}$ and $40 \mathrm{~mA}$ at a continuous speed of $0.02^{\circ}$ per second, and a scan range from $20^{\circ}$ to $90^{\circ}$ [12].

Roughness parameters (average roughness, Ra; maximum height of the profile, Rt; average maximum height of the profile, $\mathrm{Rz}$; and root mean square roughness, $\mathrm{Rq}$ ) were assessed by profilometry (Dektak 150-d; Veeco, Plainview, NY, USA) with a cutoff of $0.25 \mathrm{~mm}$ at $0.05 \mathrm{~mm} / \mathrm{s}$ over $12 \mathrm{~s}(\mathrm{n}=5)$ [23]. A goniometer (Ramé-Hart 100-00; Ramé-Hart Instrument Co., Succasunna, NJ, USA) was used to analyze the water contact angle and surface free energy by the sessile drop method $(n=5)$. For this test, the liquids used were water (polar component) and diiodomethane (dispersive component) (15 $\mu \mathrm{L}$ of each drop) [12]. Especially for this dependent variable, the test was performed on the TiZr M and TiZr SLA discs as soon as they were removed from the sterile package provided by the company. Therefore, the liquid's interaction with the surface could be evaluated as supplied. Vickers hardness was evaluated by means of an indenter (Shimadzu, HMV-2 Micro Hardness Tester, Shimadzu Corporation, Kyoto, Japan) $(\mathrm{n}=5)$. The test was performed by the application of $0.5 \mathrm{kgf}$ for $15 \mathrm{~s}$ at four randomly distributed points in each sample. The following formula was used to calculate the values of Vickers hardness: $\mathrm{Hv}=1.8544$

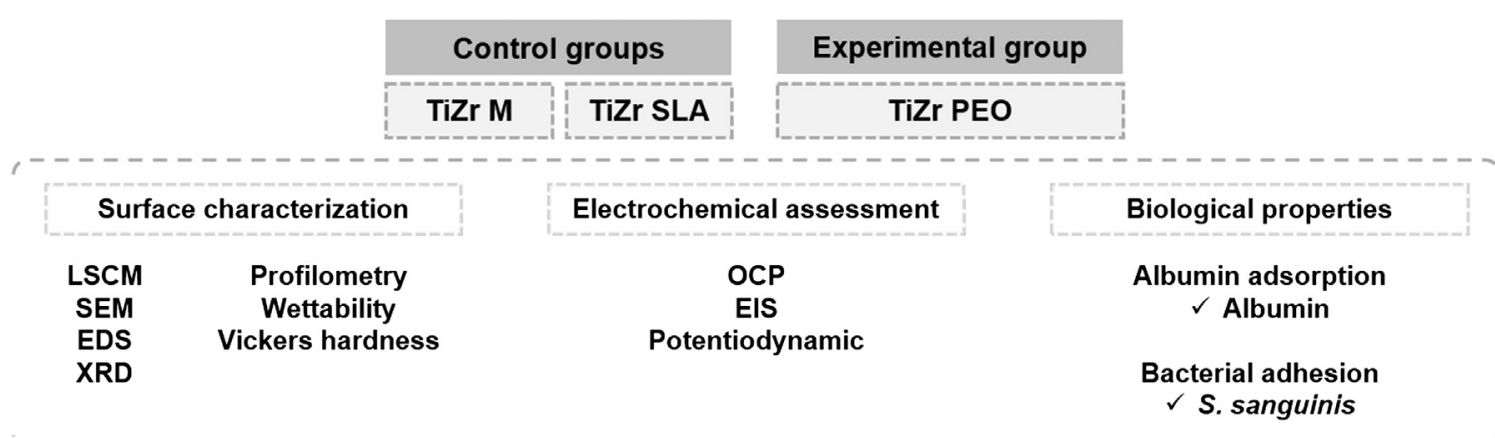

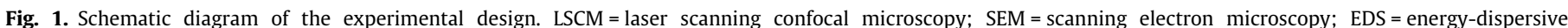
spectroscopy; XRD = X-ray diffractometry; OCP = open circuit potential; and EIS = electrochemical impedance spectroscopy. 
$\mathrm{P} / \mathrm{d}^{2}$, in which $\mathrm{P}=$ applied load and $\mathrm{d}=$ length of the diagonals of indentations [23].

\subsection{Electrochemical assessment}

The electrochemical behavior of TiZr surfaces was assessed following our previous protocol [12,22,24]. A standardized method of three-electrode cells, as required by ASTM International (formerly the American Society for Testing and Materials - ASTM) (G61-86 and G31-72), associated with a potentiostat (Interface 1000, Gamry Instruments, Warminster, PA, USA), was adopted.

The samples were placed in contact with $10 \mathrm{~mL}$ of simulated body fluid (SBF) at $37 \pm 1{ }^{\circ} \mathrm{C}(\mathrm{pH} 7.4)$ prepared as previously determined [25]. First, a cathodic potential ( $-0.9 \mathrm{~V}$ vs. SCE) was applied for $10 \mathrm{~min}$ to standardize the oxide layer. Afterward, the open circuit potential (OCP) was carried out for $3600 \mathrm{~s}$ to obtain the free corrosion potential of the material. Then, electrochemical impedance spectroscopy (EIS) was acquired at frequencies between $100 \mathrm{kHz}$ and $5 \mathrm{mHz}$ with amplitude of the sinusoidal voltage signal of $10 \mathrm{mV}$ and OCP as the initial potential [12]. EIS data were analyzed by Echem Analyst software (Gamry Instruments) and used to construct Nyquist, Bode (|Z|), and phase angle plots considering the real $\left(Z^{\prime}\right)$ and imaginary $\left(Z^{\prime \prime}\right)$ components of impedance.
Finally, the samples were polarized from -0.8 to $1.8 \mathrm{~V}$ (scan rate of $2 \mathrm{mV} / \mathrm{s}$ ) to draw the potentiodynamic polarization curves, which was possible by the Tafel extrapolation method (Echem Analyst Software, Gamry Instruments) with the following parameters: $\mathrm{E}_{\text {corr }}$ (corrosion potential), $\mathrm{I}_{\text {corr }}$ (corrosion current density), Tafel slopes (bc, ba), and passivation current density $\left(\mathrm{I}_{\text {pass }}\right)$. The electrochemical tests were conducted at least five times $(n=5)$ to ensure reliability and reproducibility. For data analyses, the exposed area (in $\mathrm{cm}^{2}$ ) of each surface $(\mathrm{TiZr} \mathrm{M}=1.98$, TiZr SLA = 5.35, TiZr PEO $=4.43$ ) was considered.

\subsection{Protein adsorption}

The assessment of albumin adsorption on the Ti15Zr surfaces followed a previous protocol [17,22]. Briefly, five samples of each group were incubated in $100 \mathrm{mg} / \mathrm{mL}$ of albumin (Sigma-Aldrich) under horizontal stirring $(7.85 \mathrm{rad} / \mathrm{s})$ at $37^{\circ} \mathrm{C}$. After up to $2 \mathrm{~h}$ of incubation, samples were washed three times in phosphatebuffered saline (PBS) (Gibco Life Technologies, Gaithersburg, MD, USA) and transferred to cryogenic tubes containing $1 \mathrm{~mL}$ of PBS. Then, discs were sonicated and vortexed for $60 \mathrm{~s}$ for removal of non-adherent proteins. The solution was diluted 10 -fold, and the protein adsorption was evaluated by the bicinchoninic acid

\section{a) Streptococcus sanguinis growth}

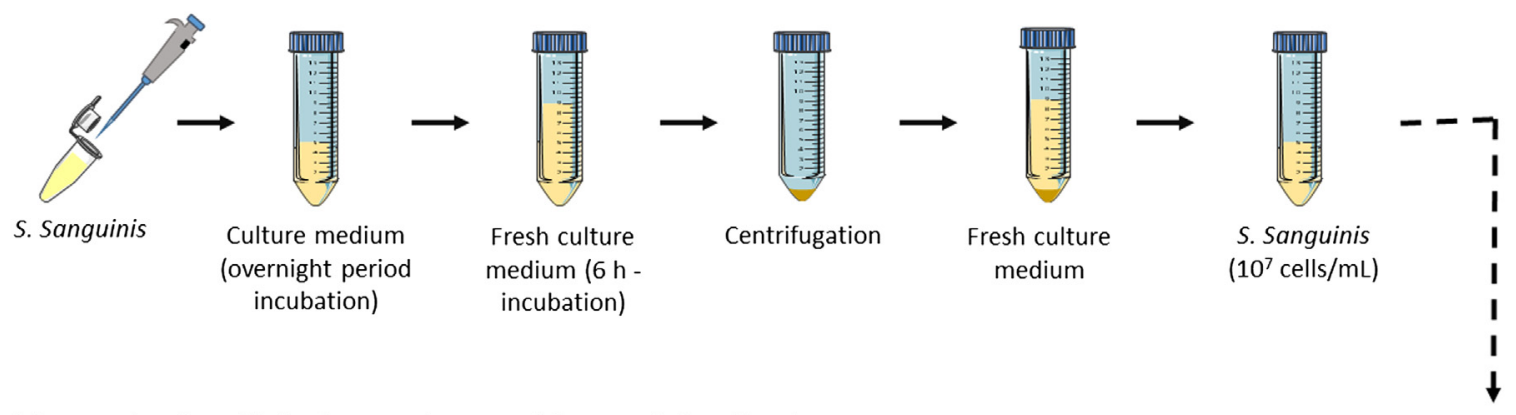

\section{b) Acquired pellicle formation and bacterial adhesion}

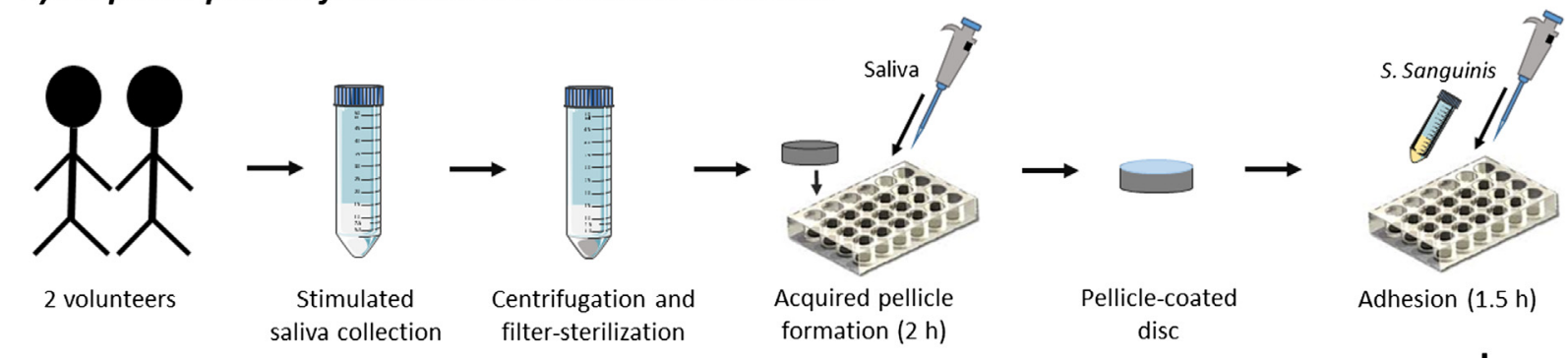

\section{c) Colony forming units counting}

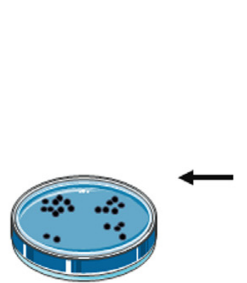

CFU counting

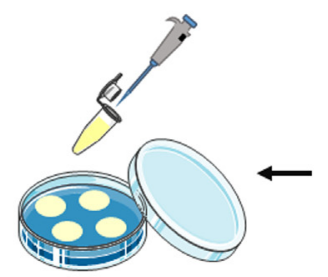

Plating and incubation $(48 \mathrm{~h})$

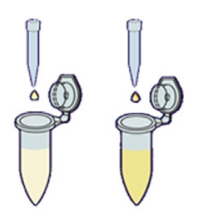

Fold-serially dilution
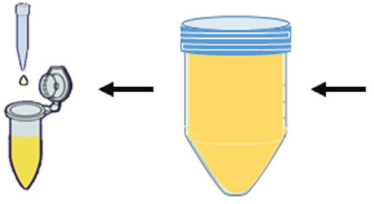

Homogenization

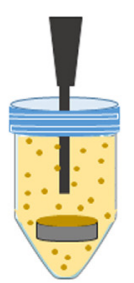

Sonication

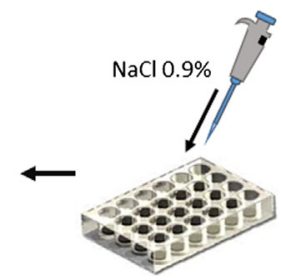

2 washes

Fig. 2. Illustrative scheme of the biofilm experimental design. 
method (BCA Kit, Sigma-Aldrich) with bovine serum albumin used as the standard.

\subsection{Bacterial adhesion}

For this investigation, the study was approved by the Local Research and Ethics Committee (79011517.9.0000.5418/2017) and followed the research recommendations of the National Health Council - Ministry of Health of Brazil.

Strains of Streptococcus sanguinis IAL $1832(100 \mu \mathrm{L})$ were grown in $5 \mathrm{~mL}$ of brain heart infusion (BHI) broth (Difco Laboratories, Becton, Dickinson and Company, Le Pont-de-Claix, France) supplemented with $1 \%$ of glucose under $10 \% \mathrm{CO}_{2}$ incubation at $37{ }^{\circ} \mathrm{C}$ without agitation during an overnight period. Then, $1 \mathrm{~mL}$ from each tube was transferred to a new tube containing $9 \mathrm{~mL}$ of $\mathrm{BHI}$ broth supplemented with $1 \%$ of glucose for $6 \mathrm{~h}$ (exponential growth phase) in the same conditions. The tubes were centrifuged ( $6000 \mathrm{~g}$ for $5 \mathrm{~min}$ at $4^{\circ} \mathrm{C}$ ) and the precipitate was resuspended in fresh BHI broth. The optical density was adjusted at $600 \mathrm{~nm}$ (OD $=1.00 \pm 0.02$ ) [24] by a spectrophotometer (DU800 Beckman Coulter, Brea, CA, USA). A final suspension of $10^{7}$ cells $/ \mathrm{mL}$ was obtained (Fig. 2a).
For simulation of clinical oral conditions, stimulated human saliva was obtained from two healthy volunteers who had been fasting for both food and water (with their informed consent). The collected saliva was centrifuged $\left(10,000 \mathrm{~g}\right.$ for $10 \mathrm{~min}$ at $\left.4{ }^{\circ} \mathrm{C}\right)$, and the supernatant was filter-sterilized and used immediately. The saliva presented $\mathrm{pH}$ around 7 . Before the acquired pellicle formation, the samples were ultrasonically cleaned in distilled water (10 $\mathrm{min}$ ) and 70\% propanol (10 min), and sterilized in an autoclave. The samples were then placed individually in a well of a sterile 24well polystyrene cell culture plate containing $1 \mathrm{~mL}$ of saliva and incubated under agitation for $2 \mathrm{~h}$ at $37{ }^{\circ} \mathrm{C}$ [24] (Fig. 2b).

The pellicle-coated discs were transferred to wells containing $100 \mu \mathrm{L}$ of $S$. sanguinis cell suspension and $900 \mu \mathrm{L}$ of BHI broth supplemented with $1 \%$ glucose. The samples were incubated for $1.5 \mathrm{~h}$ $\left(10 \% \mathrm{CO}_{2}\right.$ at $\left.37^{\circ} \mathrm{C}\right)$ (Fig. 2b). Then, the discs were washed twice in saline solution $(0.9 \% \mathrm{NaCl})$ for the removal of non-adherent cells (Fig. 2c). The discs were transferred to cryogenic tubes containing $3 \mathrm{~mL}$ of $0.9 \% \mathrm{NaCl}$. The tube was sonicated $(7 \mathrm{~W})$ for $30 \mathrm{~s}$ to disaggregate bacteria cells, and, from the homogenized suspension, an aliquot of $0.1 \mathrm{~mL}$ was 5 -fold serially diluted in $0.9 \% \mathrm{NaCl}$ and plated in mitis salivarius agar). The plates were incubated in an atmosphere of $10 \% \mathrm{CO}_{2}$ at $37{ }^{\circ} \mathrm{C}$ for $48 \mathrm{~h}$ (Fig. 2c). After the counts of
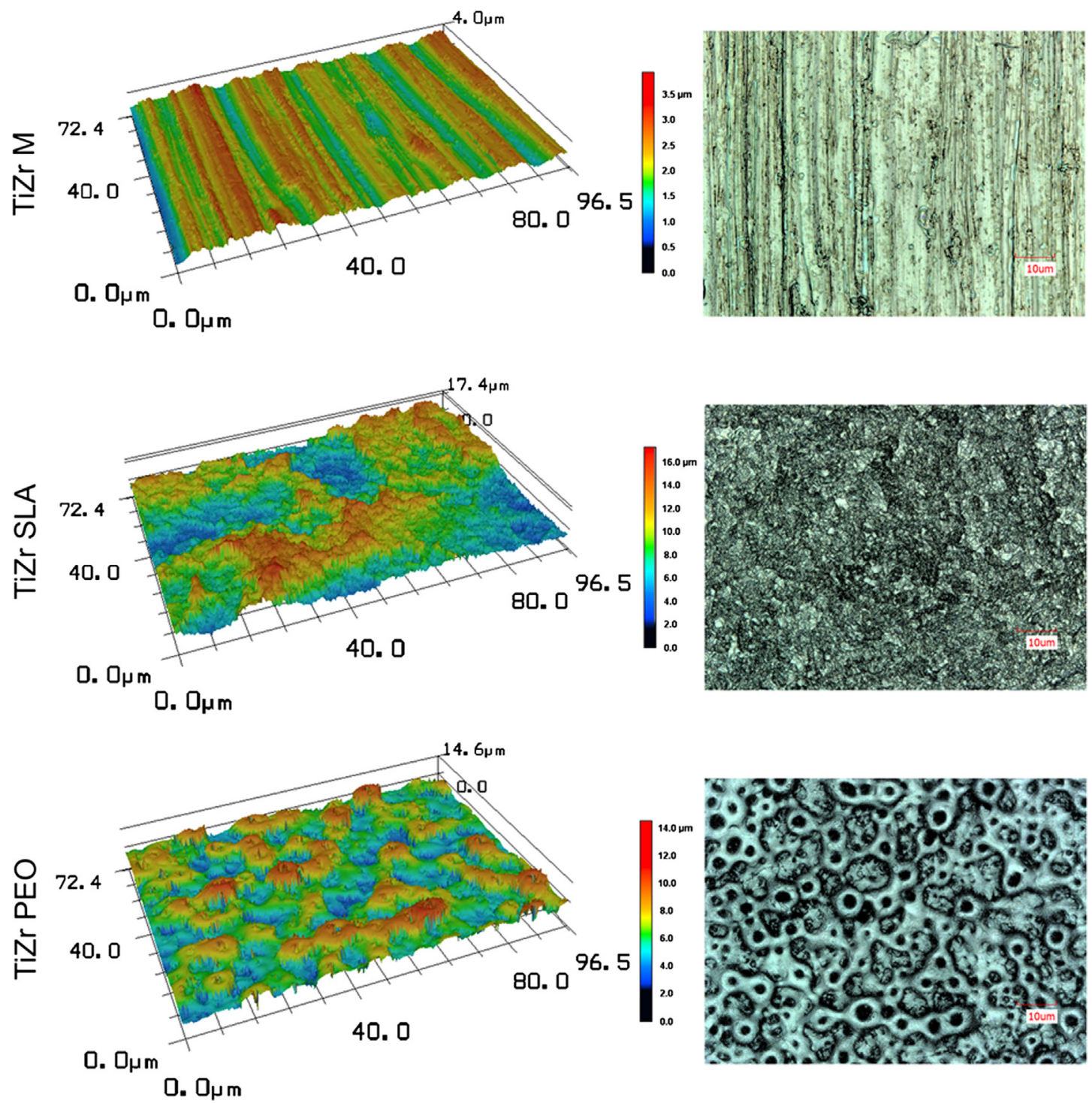

Fig. 3. Two- and three-dimensional LSCM images $(150 \times$ magnification $)$ of Ti15Zr surfaces. 
colony-forming units (CFU) were obtained, data were expressed as $\log$ of CFU per $\mathrm{cm}^{2}\left(\log \mathrm{CFU} / \mathrm{cm}^{2}\right)$, according to the disc's area as previously obtained in LSCM analysis. All assays were performed independently twice in triplicate $(2 \times 3-n=6)$.

For visualization of the bacterial cells attached to the disc surfaces, two additional discs + biofilm of each surface were fixed in Karnovsky solution (PBS; $\mathrm{pH} 7.2$ ), dehydrated in a series of ethanol washes $(60 \%, 70 \%, 80 \%$, and $90 \%$ solution for $5 \mathrm{~min}$ and $100 \%$ for 10 min), and dried aseptically. Afterward, they were gold-sputtered for analysis in SEM (JEOL-JSM-5600LV) scanned at $15 \mathrm{kV}$ at 5000 $\times$ magnification [26].

\subsection{Statistical analyses}

The Shapiro-Wilk method was performed to verify the normality of all response variables. One-way ANOVA was used to test the statistically significant differences among the surfaces with regard to roughness, surface energy, hardness, electrochemical parameters $\left(\mathrm{R}_{\mathrm{p}}, \mathrm{Q}, \mathrm{E}_{\mathrm{corr}}, \mathrm{I}_{\text {corr }}\right.$, and $\left.\mathrm{I}_{\text {pass }}\right)$, protein adsorption, and CFU counts. Tukey's HSD test was used as a post hoc technique for multiple comparisons. A mean difference significant at the 0.05 level was used for all tests (IBM SPSS Statistics for Windows, v. 21.0., IBM Corp., Armonk, NY, USA).

\section{Results}

\subsection{Surface properties}

Two- and three-dimensional images obtained by LSCM can be seen in Fig. 3. The machined surface was slightly smooth and homogeneous, with longitudinal grooves reflecting the machining process. The SLA surface presented protrusions that increased the Z-axis due to the presence of high peaks and deep valleys. The PEO surface showed topography with volcano-like pores in different diameters. It is interesting to observe the rounded contours produced by the PEO in contrast to the sharp endings of the SLA. These characteristics can be confirmed by SEM micrographs (Fig. 4). The SLA surface exhibited sandblasting holes with superposition of small pits produced by the acid-etching.

EDS mapping shown in Fig. 4 presents the chemical compositions and element concentrations of each surface. The machined and SLA surfaces presented specific elements of the alloy (Ti and $\mathrm{Zr}$ ). Although the proportions found are different from the nominal composition ( $15 \mathrm{wt} \%$ of $\mathrm{Zr}$ ), the values are acceptable, since the nominal concentration does not take into account the presence of interstitial elements such as $\mathrm{C}$ and $\mathrm{O}$. Ca and $\mathrm{P}$ were incorporated into the PEO surface at a ratio of 1.75 . The higher concentration of $\mathrm{O}$ in this surface suggests the formation of $\mathrm{Ti}$ and $\mathrm{Zr}$ oxides.

The XRD patterns (Fig. 5) show peaks of Ti for all surfaces. The crystalline structures anatase and rutile were obtained for the PEO surface, while Ti hydride ( $\mathrm{TiH}$ ) was observed for SLA surfaces.

The roughness parameters for each group are presented in Fig. 6. The SLA surface presented the highest surface roughness $(1.26 \mu \mathrm{m} \pm 0.79)$, followed by PEO $(0.41 \mu \mathrm{m} \pm 0.02)(\mathrm{p}<0.05)$. The machined surface had the lowest Ra value $(0.19 \mu \mathrm{m} \pm 0.06)(\mathrm{p}<0$. $05)$. All roughness parameters evaluated followed the same trend, confirming more irregular surfaces for the SLA group, especially if $\mathrm{Rt}$ and $\mathrm{Rz}$ are considered.

PEO treatment statistically significantly increased the surface energy and hardness of Ti15Zr alloy $(\mathrm{p}<0.05)$ when compared with those of controls (Fig. 7). For both properties, the SLA surface
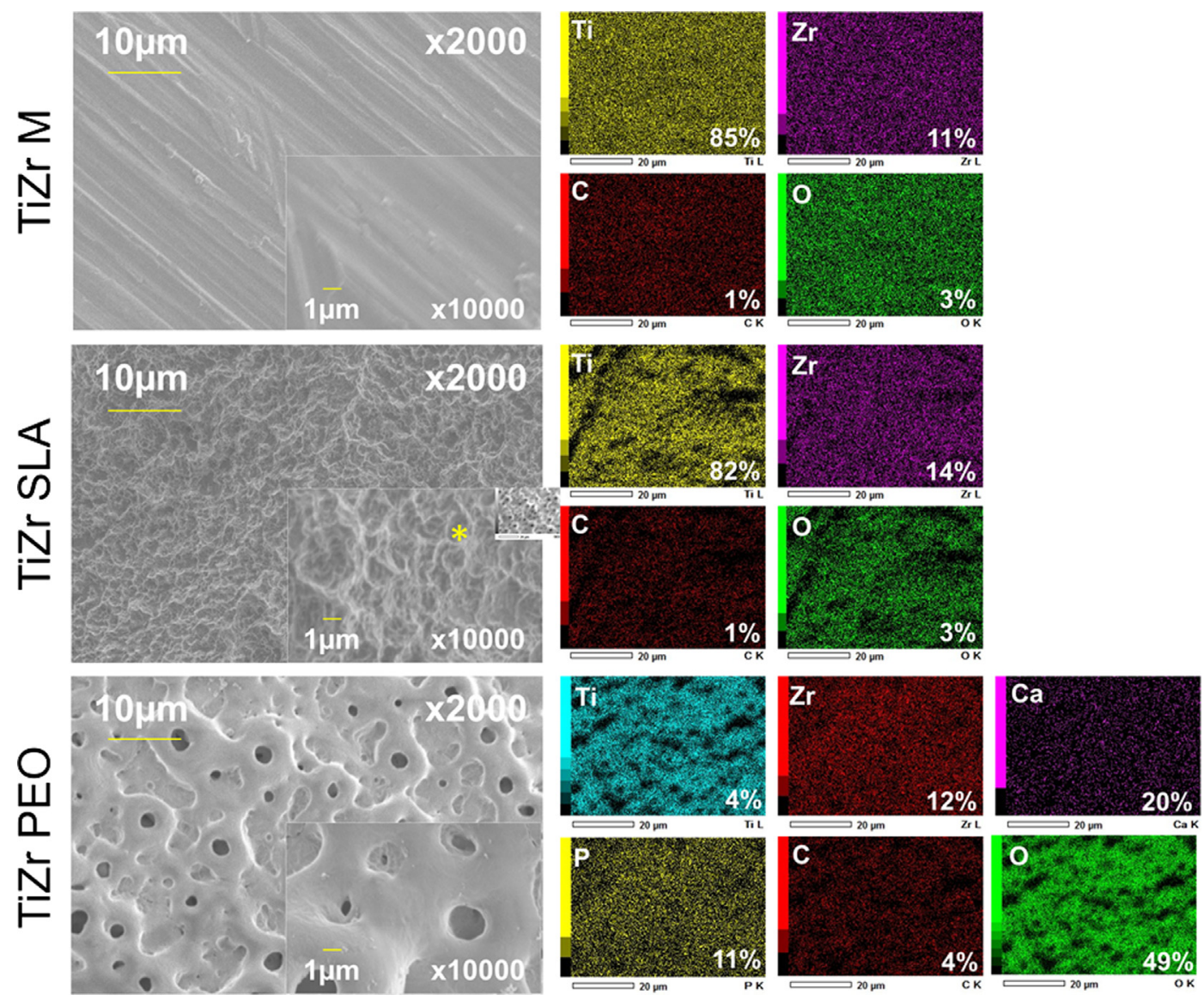

Fig. 4. SEM micrographs and chemical mapping by EDS with element concentrations (wt\%) of Ti15Zr surfaces. The asterisk indicates pits on the surface. 


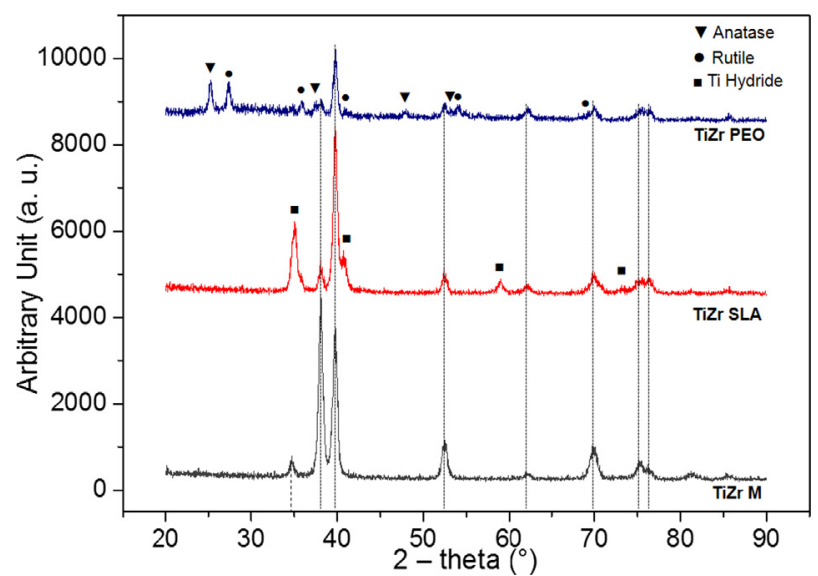

Fig. 5. X-ray diffraction patterns of Ti15Zr surfaces. The dotted lines identify the peaks of titanium.

showed the lowest values. Regarding the water contact angles, the PEO group presented the most hydrophilic surface $\left(30^{\circ}\right)$, while SLA had contact angles characteristic of a hydrophobic surface $\left(104^{\circ}\right)$. The water contact angle of machined surfaces was $89^{\circ}$.

\subsection{Electrochemical properties}

The surface electrochemical behavior was verified by OCP, EIS, and potentiodynamic tests. The evolution in OCP during $1 \mathrm{~h}$ can be observed in Fig. 8. It is clearly visible by the stability of the curves that oxide films were formed on the surface protecting the material. It seems that PEO and SLA surfaces achieved potential stability more quickly than did the machined surfaces. After $1 \mathrm{~h}$ of immersion in SBF, the PEO surface statistically significantly increased the material potential to nobler values $(139.91 \mathrm{mV} \pm 98$ .63) $(\mathrm{p}<0.05)$. There were no statistically significant differences between the machined $(3.75 \mathrm{mV} \pm 22.96)$ and SLA surfaces $(-28$. $11 \mathrm{mV} \pm 7.13)(\mathrm{p}>0.05)$.

EIS was performed for evaluation of the corrosion kinetics of Ti15Zr surfaces. Data were modeled in equivalent electrical circuits (Fig. 9). For the machined and SLA surfaces, a simple circuit consisting of Rsol (resistance of the electrolyte), $R_{p}$ (polarization resistance), and $\mathrm{Q}$ (constant phase element, $\mathrm{CPE}$ ) was used (Fig. 9a). For the PEO surface, two electrochemical interfaces were taken into

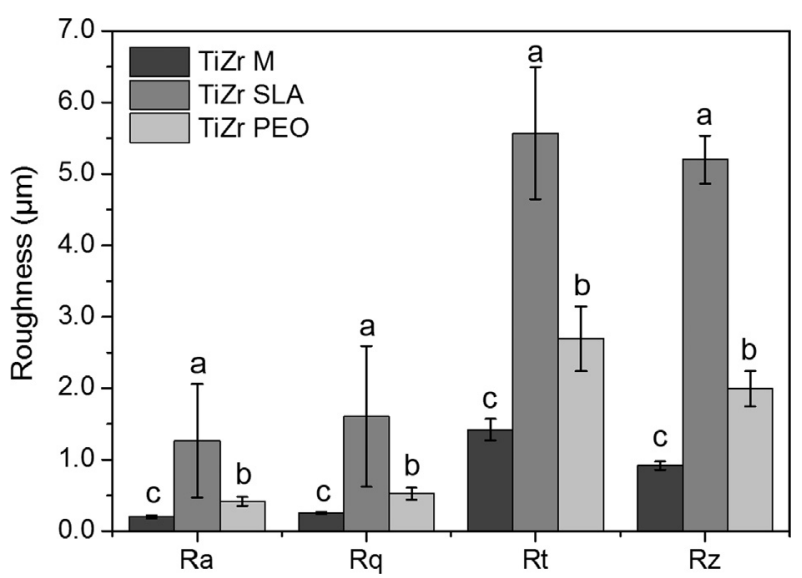

Fig. 6. Roughness parameters $(n=5)$ of Ti15Zr surfaces. Different letters indicate statistically significant differences among the groups $(\mathrm{p}<0.05$, Tukey's HSD test).

account. Thus, two pairs of elements were used in parallel: $\mathrm{Q}_{\text {out }}$ and $R_{\text {pout }}$ in series with the Warburg diffusion element $\left(W_{\text {diff }}\right)$ to represent the external porous layer, and $Q_{\text {in }}$ and $R_{\text {pin }}$ to simulate the inner compact layer (Fig. 9b). Herein the time constant of diffusion parameter (W-T) of Warburg was used to represent the transport of ionic species in the electrolyte through the porous structure.

The Nyquist diagrams can be seen in Fig. 10. PEO surfaces exhibited a much higher magnitude, being necessary to amplify the graph for visualization of the control groups. This suggests superior impedance with a higher resistance to ion exchange for PEO. Among controls, SLA showed an open arch with large diameters. In Fig. 11a, higher values of impedance were clearly visible at all frequencies for the PEO surface, revealing enhanced electrochemical behavior. Regarding the phase angle plot (Fig. 11b), the control group curves demonstrated only one time constant. Conversely, the PEO surface presented a second time constant, exhibiting a higher phase angle at high frequencies and a tendency to increase at low frequencies.

The electrical parameters obtained from EIS are described in Table 1. Chi-square $(\chi 2)$ exhibited values on the order of $10^{-2}$ to $10^{-3}$, which guarantees that the circuit was adequately fit. The PEO surface demonstrated superior polarization resistance $(\mathrm{p}<0$. $05)$, while no statistically significant difference was observed
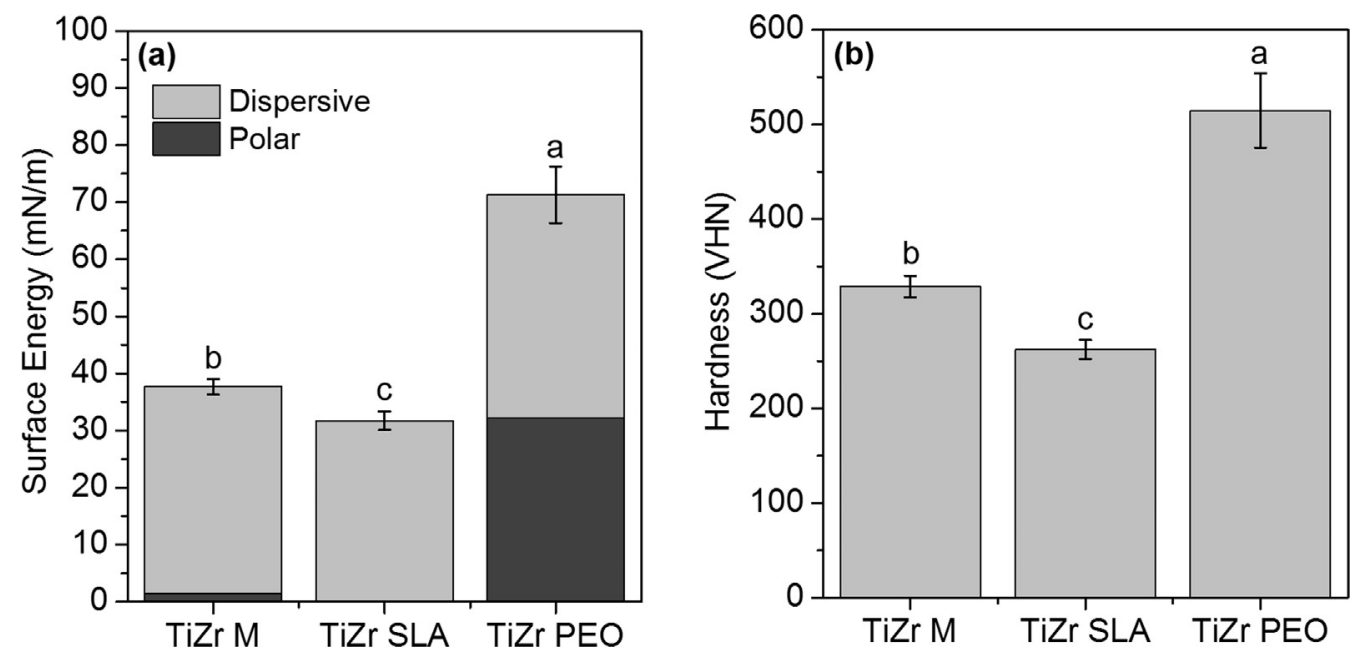

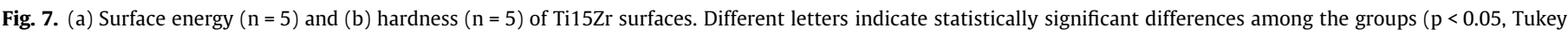
HSD test). 


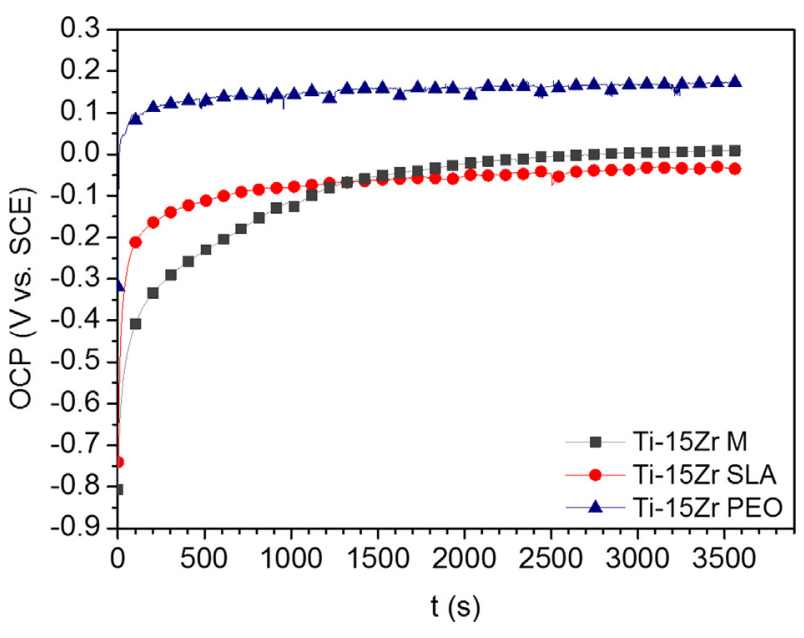

Fig. 8. Representative open circuit potential curves of Ti15Zr surfaces in SBF for $1 \mathrm{~h}$.
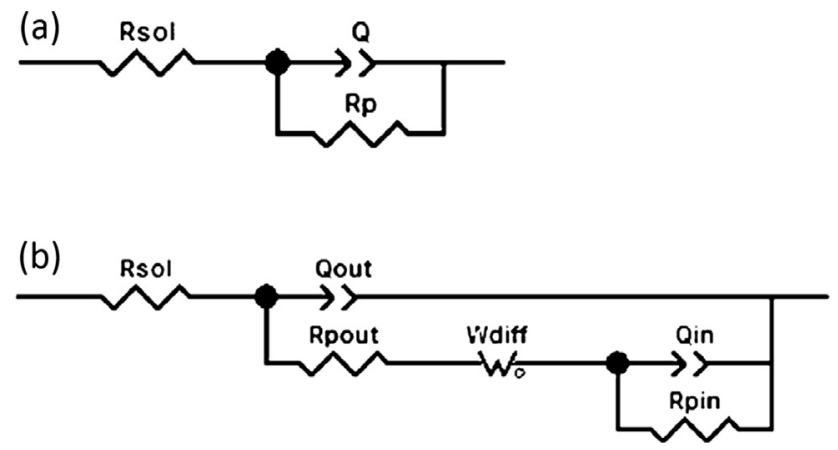

Fig. 9. Equivalent electrical circuits used to fit EIS data. (a) TiZr M and TiZr SLA groups and (b) TiZr PEO group.

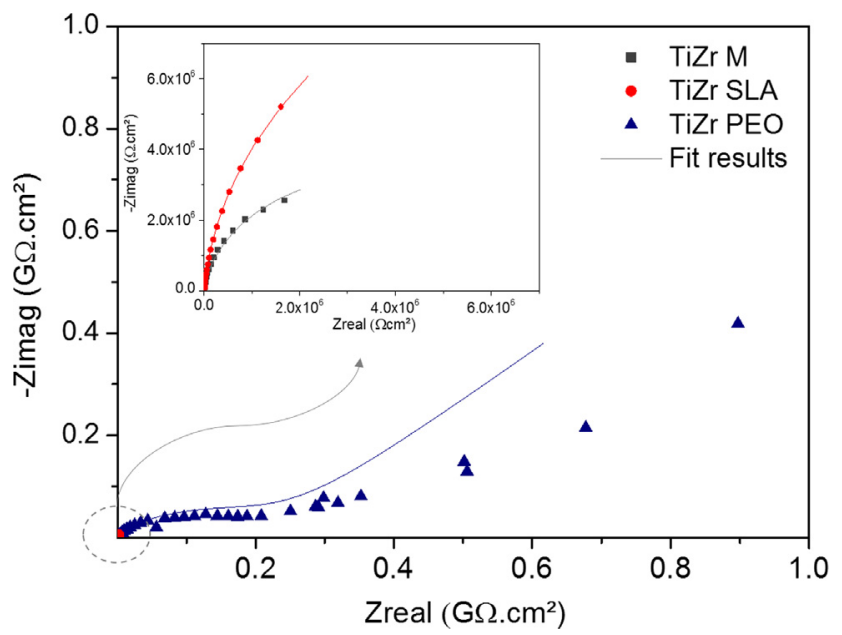

Fig. 10. Representative Nyquist diagrams of Ti15Zr surfaces in SBF.

between the control groups ( $p>0.05)$. Higher capacitance values were observed for machined surfaces $(\mathrm{p}<0.05)$. PEO showed the best electrochemical behavior with fewer ionic exchanges.

Fig. 12 shows the potentiodynamic polarization curves of the TiZr alloy for all surface types. The curves shift to the left of the graph for PEO and SLA surfaces. Improved electrochemical behavior was found for PEO, since lower current density was observed for all applied potentials. In the PEO group, the cathodic and anodic regions are symmetrical, which characterizes a ceramic-like coating. All groups exhibited a stable passivation region where the current was constant with the increase of the applied potential. There was no tendency toward depassivation and repassivation phenomena.

Concerning the electrochemical properties obtained from the potentiodynamic curves, a significant improvement of all parameters was observed for PEO surfaces (Table 2). $\mathrm{E}_{\text {corr }}$ shifted significantly to more electropositive values $(p<0.05)$, while smaller values of $\mathrm{I}_{\text {corr }}$, corrosion rate, and $\mathrm{I}_{\text {pass }}$ were found for this surface $(\mathrm{p}<0.05)$.

\subsection{Biological properties}

The protein absorption and the CFU counting of S. sanguinis are represented in Fig. 13. The PEO surface presented almost two-fold increase in albumin adsorption when compared with the controls $(\mathrm{p}<0.05)$. Both SLA and PEO surfaces presented a significant decrease of CFU counting compared with the machined group ( $p$ $<0.05)$.

The SEM micrographs revealed bacterial adhesion in all surfaces (Fig. 14). Representative images of S. sanguinis arranged as multicellular aggregates or as short streptococcal chains can be observed.

\section{Discussion}

New implant materials and surfaces have been designed in recent years to achieve greater osseointegration and treatment success. PEO is one of the most promising treatments, and this study applied such biofunctional treatment for the Ti15Zr alloy, which has been established as an alternative to cpTi and Ti6Al4V alloy, mainly because of its enhanced mechanical performance and suitable biocompatibility. In this study, we showed an improvement in surface characteristics, electrochemical behavior, and biological properties for PEO-treated Ti15Zr alloy.

The effect of PEO treatment on TiZr surface morphology is evident and, together with the element's incorporation into the oxide layer, is the main factor improving the material's properties. During the PEO process, pores arise at the sites of microdischarge channels $[18,27]$ responsible for melting the material, creating melted oxides, which are rapidly cooled in the presence of electrolytes when the discharging spark is extinguished [28,29]. This phenomenon led to the effective incorporation of $\mathrm{Ca}$ and $\mathrm{P}$ into the porous surface with a $\mathrm{Ca} / \mathrm{P}$ atomic ratio close to that of hydroxyapatite (approximately 1.67) [12]. Coatings that mimic bone structure and present such elements have been demonstrated to improve the bioactivity of PEO coating $[16,29]$ and to influence the differentiation of hBMSCs into osteoblasts [16].

Another feature that has a significant influence on the biological properties of implants relates to surface roughness. The increased roughness observed on the PEO surface when compared with the machined surface is due to the sizes of pores and their volcaniclike structure [29]. In addition, the pores have a stacking tendency that induces a more fluctuating surface [28]. Conversely, the highest roughness of the SLA surface is due to a complex hierarchical structure with deep valleys and prominent peaks produced by the mechanical-chemical process [8,30]. Previous study [31] observed a bimodal topography for the TiZr SLA surface, in which macro- (size of about 20-40 mm) and microscale features (size in the order of $2-5 \mathrm{~mm}$ ) were responsible to increase considerably the roughness when compared to that of machined surfaces. These topographic changes were also responsible for enhancing the available surface area for both groups, which has already been related to greater bone-implant contact and bonding strength, to increase 

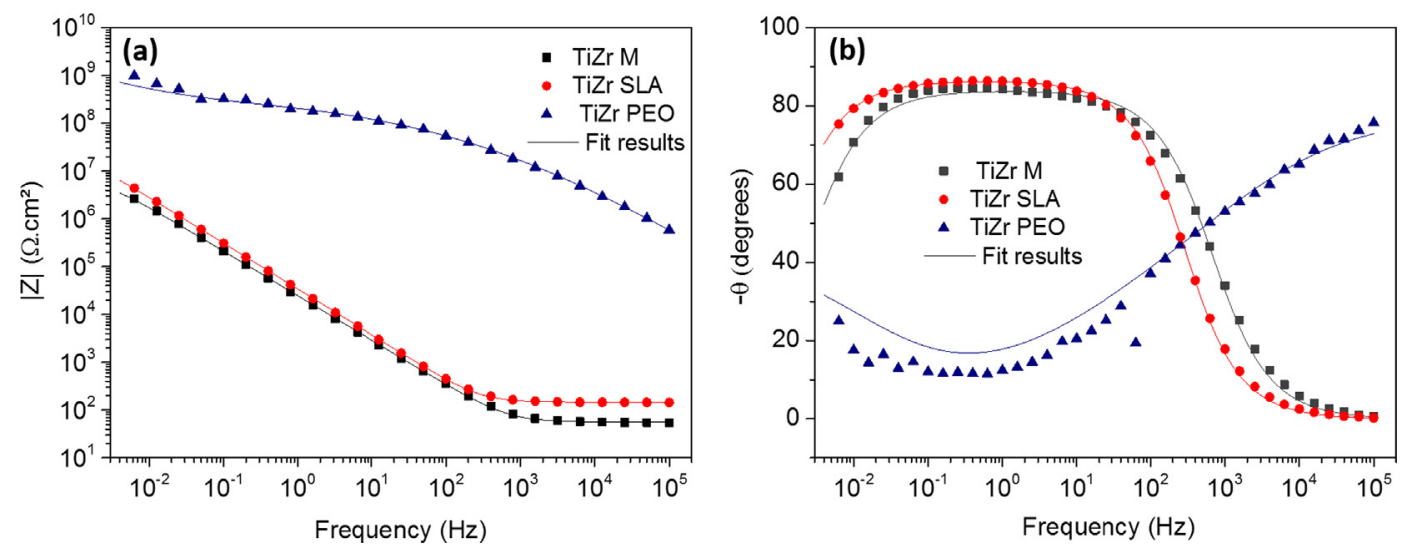

Fig. 11. Representative (a) impedance and (b) phase angle plots of Ti15Zr surfaces in SBF.

Table 1

Means and (standard deviations) of electrical parameters obtained from the equivalent circuit models of Ti15Zr surfaces.

\begin{tabular}{|c|c|c|c|c|c|c|c|c|c|c|}
\hline Groups & $\begin{array}{l}\text { Rp out } \\
\left(\mathrm{M} \Omega \cdot \mathrm{cm}^{2}\right)\end{array}$ & $\begin{array}{l}\mathrm{Rp}_{\text {in }} \\
\left(\mathrm{M} \Omega \cdot \mathrm{cm}^{2}\right)\end{array}$ & $\mathrm{Rp}_{\text {tot }}\left(\mathrm{M} \Omega \cdot \mathrm{cm}^{2}\right)$ & $\begin{array}{l}\text { Qout }\left(n \Omega^{-1} \mathrm{~s}^{\mathrm{n}} .\right. \\
\left.\mathrm{cm}^{-2}\right)\end{array}$ & $\eta_{\text {out }}$ & $\begin{array}{l}\mathrm{Q}_{\text {in }}\left(\mathrm{n} \Omega^{-1} \mathrm{~s}^{\mathrm{n}} .\right. \\
\left.\mathrm{cm}^{-2}\right)\end{array}$ & $\eta_{\text {in }}$ & $\begin{array}{l}\mathrm{Q}_{\text {tot }}\left(\mathrm{n} \Omega^{-1} \mathrm{~s}^{\mathrm{n}} .\right. \\
\left.\mathrm{cm}^{-2}\right)\end{array}$ & $\begin{array}{l}\mathrm{W}_{\text {diff }}\left(\mathrm{nS} \mathrm{s}^{-0.5}\right. \\
\left.\mathrm{cm}^{2}\right)\end{array}$ & $\chi^{2} \times 10^{-3}$ \\
\hline TiZr M & $4.40(1.47)$ & - & $4.40(1.47)^{\mathrm{a}}$ & $\begin{array}{l}11234.85 \\
(90.58)\end{array}$ & $\begin{array}{l}0.94 \\
(0.01)\end{array}$ & - & - & $\begin{array}{l}11234.85 \\
(90.58)^{\mathrm{a}}\end{array}$ & - & $\begin{array}{l}1.62 \\
(0.68)\end{array}$ \\
\hline $\begin{array}{l}\text { TiZr } \\
\text { SLA }\end{array}$ & $18.72(7.75)$ & - & $18.72(7.75)^{\mathrm{a}}$ & $\begin{array}{l}6704.67 \\
(371.08)\end{array}$ & $\begin{array}{l}0.96 \\
(0.01)\end{array}$ & - & - & $\begin{array}{l}6704.67 \\
(371.08)^{b}\end{array}$ & - & $\begin{array}{l}0.40 \\
(0.06)\end{array}$ \\
\hline $\begin{array}{l}\mathrm{TiZr} \\
\text { PEO }\end{array}$ & $\begin{array}{l}4154.76 \\
(3362.29)\end{array}$ & $\begin{array}{l}7.54 \\
(10.53)\end{array}$ & $\begin{array}{l}4162.30 \\
(3368.12)^{b}\end{array}$ & $0.80(0.83)$ & $\begin{array}{l}0.46 \\
(0.17)\end{array}$ & $0.01(0.01)$ & $\begin{array}{l}0.92 \\
(0.05)\end{array}$ & $0.81(0.84)^{\mathrm{c}}$ & $\begin{array}{l}131.77 \\
(161.93)\end{array}$ & $\begin{array}{l}12.00 \\
(4.24)\end{array}$ \\
\hline
\end{tabular}

Different letters indicate statistically significant differences among the groups ( $p<0.05$, Tukey’s HSD test).

reverse torque removal and, consequently, implant stability $[32,33]$. An anodized surface has demonstrated increased bone formation in the early stages of healing, with removal torque $45.6 \%$ higher than that of a machined implant [33]. Previous studies $[12,16,34]$ reported that cell adhesion and proliferation are driven by topographic features. A direct relationship was observed between available surface area and cell adhesion, while highly fluctuating and porous surfaces are responsible for mediating cell proliferation. Additionally, rougher surfaces allowed for cell spreading, with numerous filopodia extensions.

Wettability, obtained by means of contact angles, also affects the biological interactions of the dental implant. Only PEO surfaces presented an evidently hydrophilic feature with higher surface energy. A previous study [28] verified that the water contact angle decreases directly with the increase of calcium glycerophosphate concentration in the electrolytic solution used for PEO. The SLA treatment generated a hydrophobic surface, as reported previously [35]. This result may be due to the hierarchically structured topography with different-length scales that can cause hydrophobic water-repellent behavior [36]. Regarding the high values of water contact angles found for machined surfaces, the presence of adsorbed hydrocarbon contaminants can explain this behavior [36]. With these results, the surface energy might be the main property that favored the increased adsorption of albumin on PEO surfaces. In addition, the coating chemical composition, containing $\mathrm{Ca}, \mathrm{P}$, and hydroxyl $\left(\mathrm{OH}^{-}\right)$ions may also have influenced protein adsorption. It is known that cations like $\mathrm{Ca}$ are attracted by negatively charged surfaces, encouraging also the adsorption of proteins [37]. Its occurs by the interaction between the albumin with Ca ions through electrostatic forces, and by the formation of a Ca bridge between the albumin and $\mathrm{OH}^{-}$groups on the surface of $\mathrm{Ti}[38,39]$. Moreover, the adsorption of proteins may have been favored by the presence of pores and a rough surface that provides a large number of anchorage sites. Increased protein adsorption to the implant is important to mediate the interaction of osteoblastic cells with the implant material, consequently accelerating osseointegration $[35,40]$.

In addition to improved protein adsorption, PEO treatment presents even lower CFU counts. A previous study also found a reduced count of anaerobic bacteria for PEO surfaces [14]. It is known that PEO deposition parameters strongly influence antibacterial properties, relative to the formation of crystalline phases, oxides, and hydroxyapatite. With the exception of Ti crystalline phases, no traces of $\mathrm{Ca}-, \mathrm{P}-$, and $\mathrm{Zr}$-containing phases were detected via XRD, which could be due either to concentrations being below the detection limit of this analysis or to the compounds being in an amorphous form [41]. Varying the deposition of parameters possibly favors the growth of bacteria or even sup-

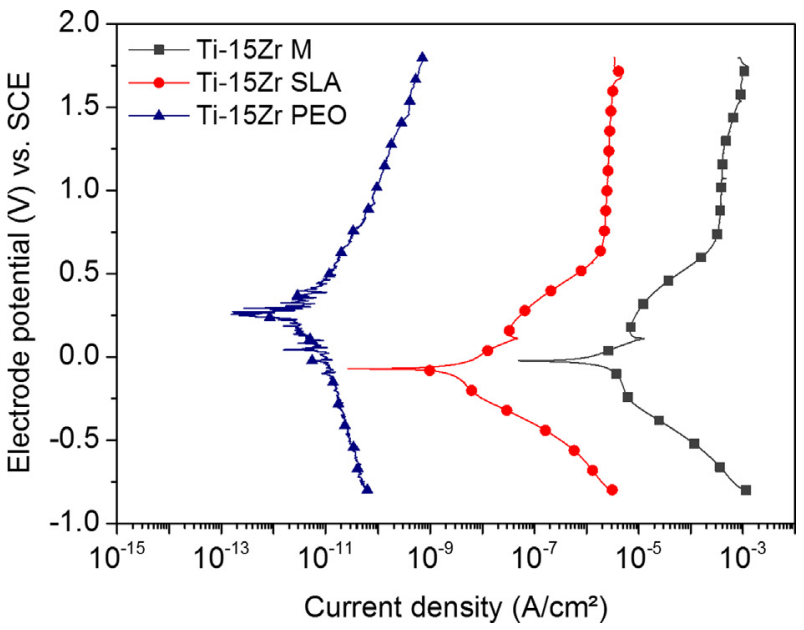

Fig. 12. Representative potentiodynamic polarization curves of Ti15Zr surfaces in SBF. 
Table 2

Mean and (standard deviation) values of electrochemical parameters obtained from the potentiodynamic polarization curves of Ti15Zr surfaces.

\begin{tabular}{|c|c|c|c|c|c|c|}
\hline Groups & $\mathrm{E}_{\text {corr }}(\mathrm{mV})$ vs. SCE & $I_{\text {corr }}\left(\mathrm{nA} \mathrm{cm}^{-2}\right)$ & $\mathrm{b}_{\mathrm{a}}\left(\mathrm{mV} \mathrm{dec}^{-1}\right)$ & $-\mathrm{b}_{\mathrm{c}}\left(\mathrm{mV} \mathrm{dec}{ }^{-1}\right)$ & $\mathrm{I}_{\text {pass }}\left(\mathrm{nA} \mathrm{cm}^{-2}\right)$ & Corrosion rate $(\mathrm{mpy}) \times 10^{-4}$ \\
\hline TiZr M & $-22.78(29.38)^{b}$ & $18.73(6.82)^{\mathrm{a}}$ & $0.33(0.04)$ & $0.29(0.03)$ & $5468.43(173.06)^{\mathrm{a}}$ & $85.55(31.00)^{a}$ \\
\hline TiZr SLA & $-66.08(11.60)^{b}$ & $4.30(0.54)^{\mathrm{b}}$ & $0.28(0.04)$ & $0.24(0.01)$ & $3236.91(33.86)^{\mathrm{b}}$ & $19.73(2.52)^{\mathrm{a}}$ \\
\hline TiZr PEO & $248.18(148.88)^{\mathrm{a}}$ & $0.01(0.01)^{\mathrm{c}}$ & $0.64(0.30)$ & $1.26(0.24)$ & $0.10(0.07)^{\mathrm{c}}$ & $0.04(0.02)^{\mathrm{b}}$ \\
\hline
\end{tabular}

Different letters indicate statistically significant differences among the groups ( $p<0.05$, Tukey's HSD test).
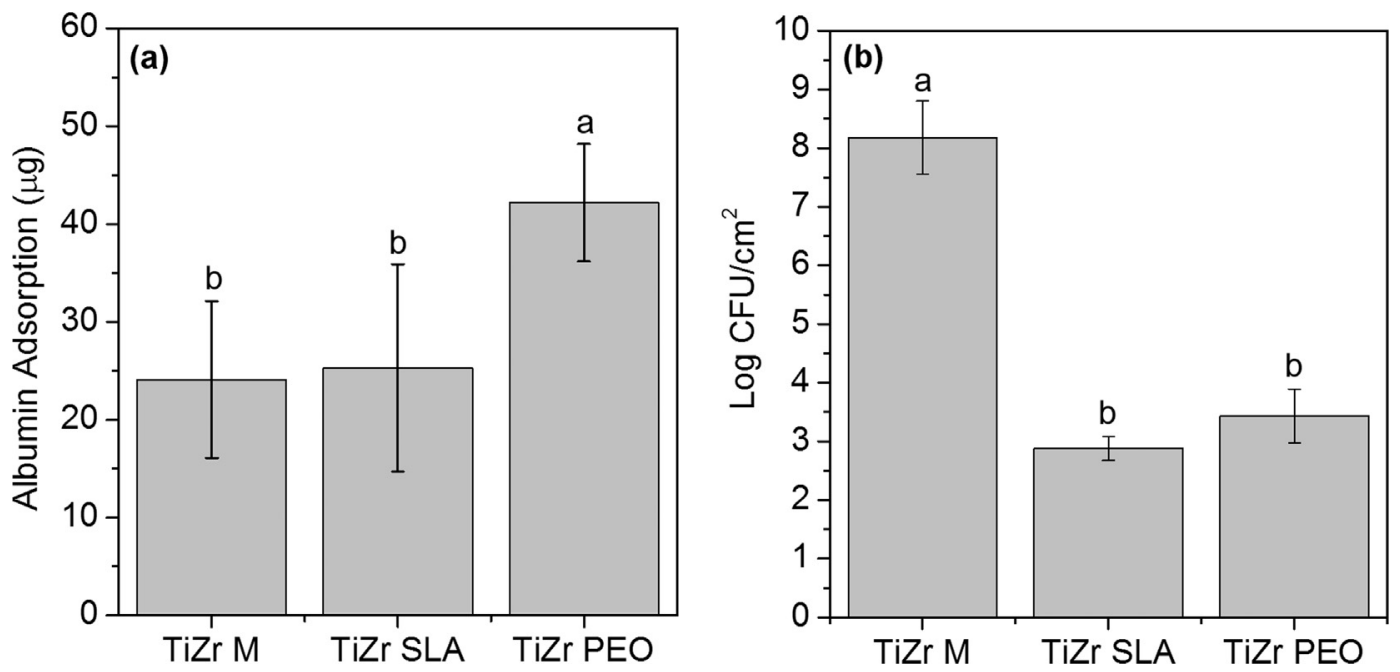

Fig. 13. (a) Albumin adsorption and (b) CFU $\left(\log _{10}\right) / \mathrm{cm}^{2}$ at $2 \mathrm{~h}$ for Streptococcus sanguinis biofilm exposed to Ti15Zr surfaces.

TiZr M

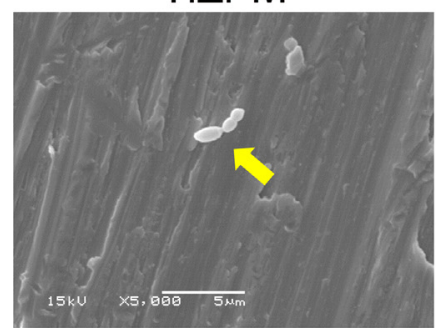

TiZr SLA

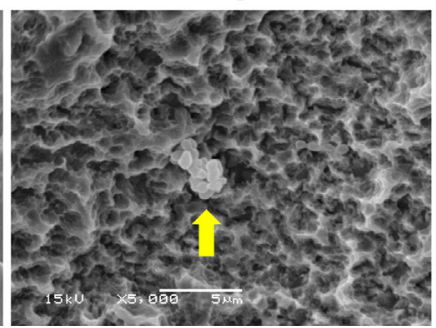

TiZr PEO

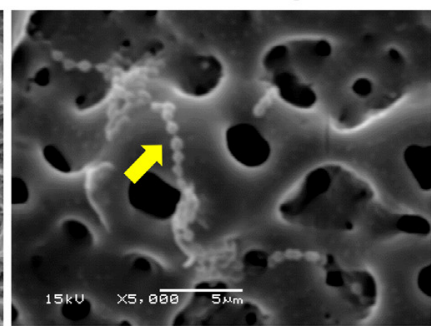

Fig. 14. SEM micrographs of biofilms formed on TiZr surfaces at $5000 \times$ magnification (scale bar $=5 \mu \mathrm{m}$ ). The arrows indicate CFU arrangements.

presses some of them, such as Staphylococcus epidermidis [42]. It was expected that $\mathrm{TiO}_{2}$ and $\mathrm{ZrO}_{2}$, as well as their crystalline phases found in PEO surfaces, could influence bacterial adhesion, since the anatase phase of $\mathrm{TiO}_{2}$ was related to the promotion of biofilm reduction of oral streptococci [43], and both crystalline phases of $\mathrm{TiO}_{2}$ were responsible for preventing the adhesion of Escherichia coli bacteria [15]. Furthermore, $\mathrm{ZrO}_{2}$-based surfaces, in comparison with $\mathrm{TiO}_{2}$ surfaces, promoted slightly less bacterial adhesion on both amorphous and crystalline structures [44]. In addition to PEO, the SLA surface also presented a reduction in CFU counts, which may be a result of its lower surface energy being less attractive to bacterial adhesion $[45,46]$. However, a previous study investigated biofilm formation in the period of 5-7 days and observed higher numbers of bacteria adhering to SLA surfaces [47]. Such contradictory findings can be explained by the fact that high roughness seems to be a minor factor in the initial adhesion phase of biofilm formation $[48,49]$, but it can influence the mature biofilm [47]. Thus, further studies are needed to ascertain the influence of these surfaces on bacterial adhesion. Besides, this study analyzed just the initial bacterial adhesion of only one species of bacteria; it would be interesting to evaluate the interaction of mature multispecies biofilm with such surfaces.

Regarding surface hardness, an improvement in this property can prevent the release of elements and harmful debris into surrounding tissues [28]. SLA surface exhibited significantly lower hardness than the other ones. An extensive study [31] on the mechanical properties of TiZr SLA surface showed that this material does not have sufficient ability to accommodate stresses by plastic deformation promoted by SLA treatment, which can impair the beneficial effect of this process on the mechanical performance of the material. This may be the driven force toward the decreasing in surface hardness for the SLA group in the present study. On the other hand, PEO showed the highest hardness among surfaces, which may be related to the formation of a thick and compact oxide film on Ti15Zr alloy that has, in its composition, the rutile crystalline phase that is related to increased hardness and coating resistance $[12,17]$. This result is interesting, since the Ti15Zr material is normally used to manufacture narrow-diameter implants that present a decrease in mechanical resistance [50], which must be compensated by the properties of materials used. The features 
found in the oxide layer for the PEO surface also ensured greater electrochemical behavior, which may protect the implant from degradation processes due to mechanical requirements as well as exposure to corrosive environments [3]. This may influence the response of peri-implant tissue to released ions and particles, reducing adverse effects such as inflammatory reactions and bone resorption.

The surface obtained by PEO showed more electropositive potentials, which can reduce the tendency to corrosion due to the formation of a stable and protective oxide layer [12]. Also, much higher values of impedance and polarization resistance were observed by EIS, reflecting significantly lower values of capacitance. The inner dense layer created by PEO was firmly attached to the substrate [28], which increased the corrosion resistance of the material acting as an efficient barrier to ion diffusion through the coating and avoiding electrochemical dissolution [19,28]. As mentioned previously, a finite-length $\mathrm{W}_{\text {diff }}$ was included in series with the resistance of the porous layer for adequate fit with the impedance and phase angle slope for PEO surfaces [12,18,19]. Normally, the use of the Warburg diffusion element is a way to represent the diffusion phenomena that occur in an early stage of immersion [12] and the mass-transfer processes inside the outer layer [18]. With respect to SLA surfaces, there is no consensus in the literature regarding its effect on corrosion resistance. In this study, a significantly lower value of capacitance, $\mathrm{I}_{\text {corr }}$, and $\mathrm{I}_{\text {pass }}$ was observed when compared with that of the machined group. It is known that etched surfaces can form a TiH intermediate layer that was detected by means of XRD in this study, which can act protecting the surface against corrosion, favoring the electrochemical results [51].

Concerning potentiodynamic polarization curves, PEO exhibits greater passive behavior, since the current density increases very slowly with the potential, maintaining a minimum difference in the corrosion current density from the beginning of the anodic region to its end. The coating produced may present throughpores or micro-cracks that provide paths for permeation or penetration of the solution [52], which maintains constant low levels of ion exchange. Even so, both $\mathrm{I}_{\text {corr }}$ and corrosion rate parameters obtained for PEO surfaces were more than two orders of magnitude less than those of controls. This behavior reaffirms the electrochemical stability of the oxide film that presents the rutile phase in its constitution. In addition, PEO surfaces showed that the corrosion potential shifted positively, which can also be correlated to increased chemical stability of the coating [28].

PEO has been widely applied in several substrates, presenting favorable results in terms of biological properties and electrochemical behavior. In this study, it was no different, since PEO was successfully applied to the Ti15Zr alloy and showed noticeably enhanced outcomes for every property evaluated. Considering that the Ti15Zr alloy has shown excellent results in vivo, the greater corrosion resistance associated with the higher protein adsorption and lower biofilm formation found for PEO surfaces will further enhance the clinical success of this material. It is clear that more research is needed to assess the biocompatibility of this surface when applied to the alloy in question. Furthermore, studies with animal models or even clinical trials are crucial to establish PEO as the best alternative in this substrate.

\section{Conclusions}

In this study, we formed a biofunctional coating to the Ti15Zr alloy and compared it with commercially available surfaces (machined and SLA). PEO was successfully applied to the substrate, being the most promising option for Ti15Zr alloys and applications in dental implant manufacturing. The coating showed remarkable surface characteristics, such as high hardness, excellent surface energy, and excellent roughness. PEO also showed the greatest corrosion resistance, with the noblest electrochemical behavior for all parameters evaluated. Additionally, this surface was able to increase the adsorption of albumin on the material surface with a lower tendency to bacterial adhesion.

\section{Declarations of interest}

None.

\section{Acknowledgments}

This work was supported by the Brazilian National Council for Scientific and Technological Development (CNPq) (grant number 137562/2016-0) and by the São Paulo State Research Foundation (FAPESP), Brazil (grant numbers 2016/11470-6 and 2017/013200 ). The authors also express their gratitude to Jamille Altheman for her contributions and support at the Laboratory of Technological Plasmas at the Univ. Estadual Paulista (UNESP) and to the Brazilian Nanotechnology National Laboratory (LNNano) at the Brazilian Center of Research in Energy and Materials (CNPEM) for the LSCM and XRD facilities.

\section{References}

[1] P. Altuna, E. Lucas-Taulé, J. Gargallo-Albiol, O. Figueras-Álvarez, F. HernándezAlfaro, J. Nart, Clinical evidence on titanium-zirconium dental implants: a systematic review and meta-analysis, Int. J. Oral Maxillofac. Surg. 45 (2016) 842-850, https://doi.org/10.1016/j.ijom.2016.01.004.

[2] C.M. Iegami, P.N. Uehara, N. Sesma, C.M. Pannuti, P. Tortamano Neto, M.K. Mukai, Survival rate of titanium-zirconium narrow diameter dental implants versus commercially pure titanium narrow diameter dental implants: a systematic review, Clin. Implant Dent. Relat. Res. 19 (2017) 1015-1022, https://doi.org/10.1111/cid.12527.

[3] M. Noronha Oliveira, W.V.H. Schunemann, M.T. Mathew, B. Henriques, R.S. Magini, W. Teughels, J.C.M. Souza, Can degradation products released from dental implants affect peri-implant tissues?, J Periodontal Res. 53 (2018) 1-11, https://doi.org/10.1111/jre.12479.

[4] A.M. Kaufman, C.I. Alabre, H.E. Rubash, A.S. Shanbhag, Human macrophage response to UHMWPE, TiAIV, CoCr, and alumina particles: Analysis of multiple cytokines using protein arrays, J. Biomed. Mater. Res. Part A. 84A (2008) 464474, https://doi.org/10.1002/jbm.a.31467.

[5] R. Bayón, A. Igartua, J.J. González, U. Ruiz de Gopegui, Influence of the carbon content on the corrosion and tribocorrosion performance of Ti-DLC coatings for biomedical alloys, Tribol. Int. 88 (2015) 115-125, https://doi.org/10.1016/j. triboint.2015.03.007.

[6] Z.U. Rahman, W. Haider, L. Pompa, K.M. Deen, Electrochemical \& osteoblast adhesion study of engineered $\mathrm{TiO}_{2}$ nanotubular surfaces on titanium alloys, Mater. Sci. Eng. C. 58 (2016) 160-168, https://doi.org/10.1016/j. msec.2015.07.024.

[7] J.M. Cordeiro, V.A.R. Barão, Is there scientific evidence favoring the substitution of commercially pure titanium with titanium alloys for the manufacture of dental implants?, Mater Sci. Eng. C. 71 (2017) 1201-1215, https://doi.org/ 10.1016/j.msec.2016.10.025.

[8] X. Shi, L. Xu, K.B. Violin, S. Lu, Improved osseointegration of long-term stored SLA implant by hydrothermal sterilization, J. Mech. Behav. Biomed. Mater. 53 (2016) 312-319, https://doi.org/10.1016/j.jmbbm.2015.08.038.

[9] D. Cochran, T. Oates, D. Morton, A. Jones, D. Buser, F. Peters, Clinical field trial examining an implant with a sand-blasted, acid-etched surface, J. Periodontol. 78 (2007) 974-982, https://doi.org/10.1902/jop.2007.060294.

[10] S. Durdu, M. Usta, A.S. Berkem, Bioactive coatings on Ti6Al4V alloy formed by plasma electrolytic oxidation, Surf. Coatings Technol. 301 (2016) 85-93, https://doi.org/10.1016/j.surfcoat.2015.07.053.

[11] A.R. Rafieerad, M.R. Ashra, R. Mahmoodian, A.R. Bushroa, Surface characterization and corrosion behavior of calcium phosphate-base composite layer on titanium and its alloys via plasma electrolytic oxidation: a review paper, Mater. Sci. Eng. C. 57 (2015) 397-413, https://doi.org/10.1016/ j.msec.2015.07.058.

[12] I. da S.V. Marques, V.A.R. Barão, N.C. da Cruz, J.C. Yuan, M.F. Mesquita, A.P. Ricomini-Filho, C. Sukotjo, M.T. Mathew, Electrochemical behavior of bioactive coatings on cp-Ti surface for dental application, Corros. Sci. 100 (2015) 133146, https://doi.org/10.1016/j.corsci.2015.07.019.

[13] W. Liu, M. Cheng, T. Wahafu, Y. Zhao, H. Qin, J. Wang, X. Zhang, L. Wang, The in vitro and in vivo performance of a strontium-containing coating on the lowmodulus Ti35Nb2Ta3Zr alloy formed by micro-arc oxidation, J. Mater. Sci. Mater. Med. 26 (2015) 203, https://doi.org/10.1007/s10856-015-5533-0. 
[14] A.O. Matos, A.P. Ricomini-Filho, T. Beline, E.S. Ogawa, B.E. Costa-Oliveira, A.B. de Almeida, F.H. Nociti Junior, E.C. Rangel, N.C. da Cruz, C. Sukotjo, M.T. Mathew, V.A.R. Barão, Three-species biofilm model onto plasma-treated titanium implant surface, Colloids Surf. B Biointerfaces. 152 (2017) 354-366, https://doi.org/10.1016/j.colsurfb.2017.01.035.

[15] D. Zhao, Y. Lu, Z. Wang, X. Zeng, S. Liu, T. Wang, Antifouling properties of micro arc oxidation coatings containing $\mathrm{Cu}_{2} \mathrm{O} / \mathrm{ZnO}$ nanoparticles on Ti6Al4V, Int. J. Refract. Met. Hard Mater. 54 (2016) 417-421, https://doi.org/10.1016/j. ijrmhm.2015.10.003.

[16] M. Sowa, M. Piotrowska, M. Widziołek, G. Dercz, G. Tylko, T. Gorewoda, A.M. Osyczka, W. Simka, Bioactivity of coatings formed on Ti-13Nb-13Zr alloy using plasma electrolytic oxidation, Mater. Sci. Eng. C. 49 (2015) 159-173, https://doi.org/10.1016/j.msec.2014.12.073.

[17] T. Beline, I. da S.V. Marques, A.O. Matos, E.S. Ogawa, A.P.A.P. Ricomini-Filho, E. C. Rangel, N.C. da Cruz, C. Sukotjo, M.T. Mathew, R. Landers, R.L.X. Consani, M.F. Mesquita, V.A.R. Barao, V.A.R. Barão, Production of a biofunctional titanium surface using plasma electrolytic oxidation and glow-discharge plasma for biomedical applications, Biointerphases. 11 (2016) 11013, https://doi.org/ 10.1116/1.4944061.

[18] M. Mohedano, E. Matykina, R. Arrabal, A. Pardo, M.C. Merino, Metal release from ceramic coatings for dental implants, Dent. Mater. 30 (2014) e28-e40, https://doi.org/10.1016/j.dental.2013.12.011.

[19] E. Matykina, R. Arrabal, B. Mingo, M. Mohedano, A. Pardo, M.C. Merino, In vitro corrosion performance of PEO coated $\mathrm{Ti}$ and Ti6Al4V used for dental and orthopaedic implants, Surf. Coatings Technol. 307 (2016) 1255-1264, https:// doi.org/10.1016/j.surfcoat.2016.08.018.

[20] M.-J. Hwang, H.-R. Choi, H.-J. Song, Y.-J. Park, Characterization and colorization of microarc-oxidized layers of binary titanium alloys, J. Alloys Compd. 732 (2018) 95-106, https://doi.org/10.1016/j.jallcom.2017.10.181.

[21] E. Urbańczyk, A. Krząkała, A. Kazek-Kęsik, J. Michalska, A. Stolarczyk, G. Dercz, W. Simka, Electrochemical modification of Ti-13Nb-13Zr alloy surface in phosphate based solutions, Surf. Coatings Technol. 291 (2016) 79-88, https:// doi.org/10.1016/j.surfcoat.2016.02.025.

[22] J.M. Cordeiro, T. Beline, A.L.R. Ribeiro, E.C. Rangel, N.C. da Cruz, R. Landers, L.P. Faverani, L.G. Vaz, L.M.G. Fais, F.B. Vicente, C.R. Grandini, M.T. Mathew, C. Sukotjo, V.A.R. Barão, Development of binary and ternary titanium alloys for dental implants, Dent. Mater. 33 (2017) 1244-1257, https://doi.org/10.1016/ j.dental.2017.07.013.

[23] L.P. Faverani, W.G. Assunção, P.S.P. de Carvalho, J.C.-C. Yuan, C. Sukotjo, M.T. Mathew, V.A. Barao, Effects of dextrose and lipopolysaccharide on the corrosion behavior of a Ti-6Al-4V alloy with a smooth surface or treated with double-acid-etching, PLoS One. 9 (2014) e93377, https://doi.org/10.1371/ journal.pone.0093377.

[24] V.A.R. Barão, A.P. Ricomini-Filho, L.P. Faverani, A.A. Del Bel Cury, C. Sukotjo, D. R. Monteiro, J.C.-C. Yuan, M.T. Mathew, R.C. do Amaral, M.F. Mesquita, W.J. da Silva, W.G. Assunção, The role of nicotine, cotinine and caffeine on the electrochemical behavior and bacterial colonization to cp-Ti, Mater. Sci. Eng. C. 56 (2015) 114-124, https://doi.org/10.1016/j.msec.2015.06.026.

[25] L. Muller, F.A. Muller, Preparation of SBF with different $\mathrm{HCO}_{3}^{-}$content and its influence on the composition of biomimetic apatites, Acta Biomater. 2 (2006) 181-189, https://doi.org/10.1016/j.actbio.2005.11.001.

[26] T. Pereira-Cenci, D.M. Deng, E.A. Kraneveld, E.M.M. Manders, A.A. Del Bel Cury, J.M. ten Cate, W. Crielaard, The effect of Streptococcus mutans and Candida glabrata on Candida albicans biofilms formed on different surfaces, Arch. Oral Biol. 53 (2008) 755-764, https://doi.org/10.1016/j.archoralbio.2008.02.015.

[27] S. Durdu, Ö.F. Deniz, I. Kutbay, M. Usta, Characterization and formation of hydroxyapatite on Ti6Al4V coated by plasma electrolytic oxidation, J. Alloys Compd. 551 (2013) 422-429, https://doi.org/10.1016/j.jallcom.2012.11.024.

[28] X. Shi, Q. Wang, F. Wang, S. Ge, Effects of electrolytic concentration on properties of micro-arc film on Ti6Al4V alloy, Min. Sci. Technol. 19 (2009) 220-224, https://doi.org/10.1016/S1674-5264(09)60042-9.

[29] H. Wang, F. Liu, X. Xiong, S. Ke, X. Zeng, P. Lin, Structure, corrosion resistance and in vitro bioactivity of $\mathrm{Ca}$ and $\mathrm{P}$ containing $\mathrm{TiO}_{2}$ coating fabricated on NiTi alloy by plasma electrolytic oxidation, Appl. Surf. Sci. 356 (2015) 1234-1243, https://doi.org/10.1016/j.apsusc.2015.08.228.

[30] M. Murphy, M.S. Walczak, A.G. Thomas, N. Silikas, S. Berner, R. Lindsay, M. Murphy, M.S. Walczak, A.G. Thomas, N. Silikas, S. Berner, R. Lindsay, Toward optimizing dental implant performance: Surface characterization of $\mathrm{Ti}$ and TiZr implant materials, Dent. Mater. 33 (2016) 43-53, https://doi.org/10.1016/ j.dental.2016.10.001.

[31] A.E. Medvedev, A. Molotnikov, R. Lapovok, R. Zeller, S. Berner, P. Habersetzer, F. Dalla, Torre, microstructure and mechanical properties of Ti-15Zr alloy used as dental implant material, J. Mech. Behav. Biomed. Mater. 62 (2016) 384-398, https://doi.org/10.1016/j.jmbbm.2016.05.008.

[32] S. Cho, The removal torque of titanium screw inserted in rabbit tibia treated by dual acid etching, Biomaterials. 24 (2003) 3611-3617, https://doi.org/ 10.1016/S0142-9612(03)00218-7.
[33] C.N. Elias, Y. Oshida, J.H.C. Lima, C.A. Muller, Relationship between surface properties (roughness, wettability and morphology) of titanium and denta implant removal torque, J. Mech. Behav. Biomed. Mater. 1 (2008) 234-242, https://doi.org/10.1016/j.jmbbm.2007.12.002.

[34] J.I. Rosales-Leal, M.A. Rodríguez-Valverde, G. Mazzaglia, PJ. RamónTorregrosa, L. Díaz-Rodríguez, O. García-Martínez, M. Vallecillo-Capilla, C. Ruiz, M.A. Cabrerizo-Vílchez, Effect of roughness, wettability and morphology of engineered titanium surfaces on osteoblast-like cell adhesion, Colloids Surf. A Physicochem. Eng. Asp. 365 (2010) 222-229, https://doi.org/10.1016 j.colsurfa.2009.12.017.

[35] Y. Xie, J. Li, Z.M. Yu, Q. Wei, Nano modified SLA process for titanium implants Mater. Lett. 186 (2017) 38-41, https://doi.org/10.1016/j.matlet.2016.08.079.

[36] F. Rupp, L. Scheideler, D. Rehbein, D. Axmann, J. Geis-Gerstorfer, Roughness induced dynamic changes of wettability of acid etched titanium implant modifications, Biomaterials 25 (2004) 1429-1438, https://doi.org/10.1016/j. biomaterials.2003.08.015.

[37] Y. Mao, J. Yan, L. Wang, W. Dong, Y. Jia, X. Hu, X. Wang, Formation and properties of bioactive barium titanate coatings produced by plasma electrolytic oxidation, Ceram. Int. (2018), https://doi.org/10.1016/j. ceramint.2018.04.115.

[38] L. Burgos-Asperilla, M.C. García-Alonso, M.L. Escudero, C. Alonso, Study of the interaction of inorganic and organic compounds of cell culture medium with a Ti surface, Acta Biomater. 6 (2010) 652-661, https://doi.org/10.1016/j. actbio.2009.06.019.

[39] E. Martínez Campos, A. Santos-Coquillat, B. Mingo, R. Arrabal, M. Mohedano, A. Pardo, V. Ramos, J.-L. López Lacomba, E. Matykina, Albumin loaded PEO coatings on $\mathrm{Ti}-$ potential as drug eluting systems, Surf. Coatings Technol. 283 (2015) 44-51, https://doi.org/10.1016/j.surfcoat.2015.10.045.

[40] Y. Shibata, Y. Tanimoto, A review of improved fixation methods for dental implants. Part I: surface optimization for rapid osseointegration, J. Prosthodont. Res. 59 (2015) 20-33, https://doi.org/10.1016/j.jpor.2014.11.007.

[41] A. Kazek-Kesik, M. Krok-Borkowicz, A. Jakóbik-Kolon, E. Pamula, W. Simka Biofunctionalization of Ti-13Nb-13Zr alloy surface by plasma electrolytic oxidation. Part I, Surf. Coat. Technol. 276 (2015) 23-30, https://doi.org/ 10.1016/j.surfcoat.2015.06.035.

[42] S. Lugovskoy, D. Weiss, U. Tsadok, A. Lugovskoy, Morphology and antimicrobial properties of hydroxyapatite-titanium oxide layers on the surface of Ti-6Al-4V alloy, Surf. Coat. Technol. 301 (2016) 80-84, https:// doi.org/10.1016/j.surfcoat.2015.11.050.

[43] M. Dorkhan, J. Hall, P. Uvdal, A. Sandell, G. Svensäter, J.R. Davies, Crystalline anatase-rich titanium can reduce adherence of oral streptococci, Biofouling. 30 (2014) 751-759, https://doi.org/10.1080/08927014.2014.922962.

[44] A. Almaguer-Flores, P. Silva-Bermudez, R. Galicia, S.E. Rodil, Bacterial adhesion on amorphous and crystalline metal oxide coatings, Mater. Sci. Eng. C. 57 (2015) 88-99, https://doi.org/10.1016/j.msec.2015.07.031.

[45] M. Quirynen, D. van Steenberghe, Bacterial colonization of the internal part of two-stage implants. An in vivo study, Clin. Oral Implants Res. 4 (1993) 158161, https://doi.org/10.1034/j.1600-0501.1993.040307.x.

[46] W. Teughels, N. Van Assche, I. Sliepen, M. Quirynen, Effect of material characteristics and/or surface topography on biofilm development, Clin. Ora Implants Res. 17 (2006) 68-81, https://doi.org/10.1111/j.16000501.2006.01353.x.

[47] A. Almaguer-Flores, R. Olivares-Navarrete, M. Wieland, L.A. Ximénez-Fyvie, Z Schwartz, B.D. Boyan, Influence of topography and hydrophilicity on initial oral biofilm formation on microstructured titanium surfaces in vitro, Clin. Ora Implants Res. 23 (2012) 301-307, https://doi.org/10.1111/j.16000501.2011.02184.x.

[48] R. Bos, Physico-chemistry of initial microbial adhesive interactions - its mechanisms and methods for study, FEMS Microbiol. Rev. 23 (1999) 179-229, https://doi.org/10.1016/S0168-6445(99)00004-2.

[49] L. Boulangé-Petermann, J. Rault, M. Bellon-Fontaine, Adhesion of streptococcus thermophilus to stainless steel with different surface topography and roughness, Biofouling 11 (1997) 201-216, https://doi.org/10.1080/ 08927019709378331.

[50] S. Barter, P. Stone, U. Brägger, A pilot study to evaluate the success and survival rate of titanium-zirconium implants in partially edentulous patients: results after 24 months of follow-up, Clin. Oral Implants Res. 23 (2012) 873-881, https://doi.org/10.1111/j.1600-0501.2011.02231.x.

[51] L. Jonášová, F.A. Müller, A. Helebrant, J. Strnad, P. Greil, Biomimetic apatite formation on chemically treated titanium, Biomaterials 25 (2004) 1187-1194 https://doi.org/10.1016/j.biomaterials.2003.08.009.

[52] L. Cui, S. Gao, P.-P. Li, R. Zeng, F. Zhang, S.-Q. Li, E.-H. Han, Corrosion resistance of a self-healing micro-arc oxidation/polymethyltrimethoxysilane composite coating on magnesium alloy AZ31, Corros. Sci. 118 (2017) 84-95, https://doi. org/10.1016/j.corsci.2017.01.025. 